\title{
THE DATA AND SERVICES ANALYSIS OF CHINESE NSDI BASED ON BACKX MODEL
}

\author{
Wei WANG ${ }^{1,}{ }^{*}$, Mei XUE ${ }^{2}$, Chenfeng LUO $^{3}$, Xiaomeng WANG ${ }^{4}$, Bastiaan, van Loenen ${ }^{5}$ \\ ${ }^{1}$ Tianjin Institute of Surveying and Mapping, Changlin Rd. No.9, Xiqing Dist, Tianjin, China - wangwei_sgg@163.com \\ ${ }^{2}$ Chongqing Surveying Institute, Diancecun No.231, Jiangbei Dist. Chongqing, China - mayre0525@ hotmail.com \\ ${ }^{3}$ Chinese Academy of Surveying and Mapping, Lianhuachi WEST Rd. No.28, Haidian Dist, Beijing, China - chfluo@casm.ac.cn \\ ${ }^{4}$ Beijing Urban Planning and Land Resource Committee, Nanlishi Rd. No.60, Xicheng Dist, Beijing, China - roggass@163.com \\ ${ }^{5}$ Research for the Built Environment Institute of Photogrammetry and Geoinformation, TU Delft, Julianalaan 134 (Building 8) room \\ BG. WEST.660, 2628 BL Delft, The Netherlands - B.vanLoenen@tudelft.nl
}

\section{Remote Sensing for Regional SDI (UNGGIM-AP \& ISPRS TC III)}

KEY WORDS: Data and Service Analysis, Chinese NSDI, Backx Model

\begin{abstract}
:
The data and services analysis are indispensable for the refined development of SDI. This paper, taking Chinese NSDI as a study case, analyzed the data and services advantages and shortcomings of Chinese NSDI and developed a recommendable data and services framework which could improve the Chinese NSDI better services for public and private sectors from known, attainable and usable aspects by using Backx model. And the recommendation framework can also be referenced by other national and local SDI for its better services and applications.
\end{abstract}

\section{BACKGROUND}

The data and services analysis are indispensable for the refined development of SDI. A perfect SDI should provide known, attainable, and usable data and services, should realize standardized, harmonized, and up-to-date datasets and services with correct metadata, and should develop services for national sustainable development and better citizens' lives. Bastiaan van Loenen and Michel Grothe from TU Delft had deeply studied the better application methods of SDI data and services for public sectors in European INSPIRE project (Bastiaan et al., 2014, 2016). In Aug 2015, I and other three technical researchers were sponsored by UN-GGIM and NASG for the further study of geoinformation governance in TU Delft, the INSPIRE geo-governance ideal and Backx model were deeply discussed. In consideration of the common usage, Chinese NSDI is also taken as the study case by using the Backx model, some referenceable suggestions will be shown in this paper.

\section{THE BRIEF INTRODUCTION OF BACKX MODEL}

The concentric shell model developed by Backx (Backx et al., 2003) and popularized by Van Loenen is widely used in geographic information governance and geoinformation re-use (Van Loenen et al., 2014). The Backx model was also successfully used in European INSPIRE project. The Backx model has three layers from outer to inner: KNOWN, ATTAINABLE and USABLE, as shown in Figure 1.

KNOWN means that the existence of information must be known before it can be used. This can be achieved through text descriptions of information for the identification of information resources, like resource titles and abstracts, and sometimes graphics. This is also known as 'resource metadata'. If the existence of the information is known to a user (is recognizable), one must be able to find it (is discoverable). Most of the information can be achieved by search engines.

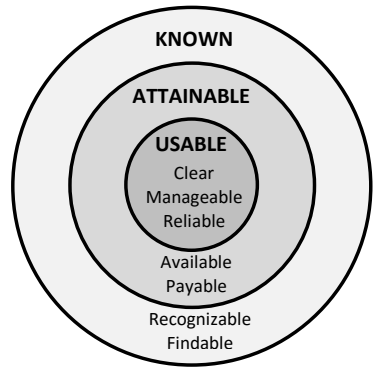

Figure 1. The Backx model and its' three layers

ATTAINALBE implies that the information can be obtained from a legal, physical and financial perspective. Legal attainability refers to the availability of information on the basis of laws and regulations. Physical attainability refers to the physical availability of the information (such as network download). The financial attainability refers to the affordability of the information.

USABLE means the information should be clear, manageable and reliable. Clear information includes the data quality description, the metadata is completed and consultant is satisfied the user. Manageable information means Information should be machine-readable and in open format. Reliable requires information should be current, consistent and complete.

\footnotetext{
* Corresponding author
} 


\section{THE CURRENT DATA AND SERVICE ANALYSIS OF CHINESE NSDI}

\subsection{The Datasets of Chinese NSDI}

The datasets of Chinese NSDI are hierarchical in three levels, the national, the provincial and the city. Different government levels are responsible for different scales datasets. The national level is the main node for data convergence and distribution, the provincial and city levels are the sub notes, and the hierarchy is a pyramid structure as showed in figure 2 . All the datasets serve the public by Tianditu (Mapword) geo-website (Pengde Li, et al., 2008).

\begin{tabular}{|c|c|c|}
\hline $\begin{array}{l}\text { National } \\
\text { Main Node }\end{array}$ & & Small-scales. 1:50,000 or less \\
\hline$\sqrt{ }$ & $\nabla$ & \multirow[b]{2}{*}{$\begin{array}{c}\text { Medium-scales. } 1: 10,000 \text { or } \\
\text { 1:5,000 By Provincial Geo } \\
\text { Administration }\end{array}$} \\
\hline $\begin{array}{c}\text { Provincial } \\
\text { sub Node }\end{array}$ & $\begin{array}{l}\text { Provincial } \\
\text { sub Node }\end{array}$ & \\
\hline$\sqrt{ }$ & $\nabla$ & \\
\hline $\begin{array}{l}\text { City sub } \\
\text { Node }\end{array}$ & $\begin{array}{l}\text { City sub } \\
\text { Node }\end{array}$ & $\begin{array}{l}\text { large-scale. } 1: 2,000 \text { or } 1: 500 \\
\text { By City Geo Administration }\end{array}$ \\
\hline
\end{tabular}

Figure 2. The Datasets organization structure of Chinese NSDI

There are two main classifications of Chinese NSDI data which are parts of China fundamental geoinformation datasets. The two classifications are Coordinate Reference Datum datasets and Multi Scales Fundamental datasets. Coordinate Reference Datum datasets contains 33 A-class GNSS points and 818 Bclass GNSS points, which forms the China geospatial information reference network, and the gravity control network which contains 137 gravity reference points (18 fiducial points and 119 basis points) (Deren Li, 2002). All these infrastructures formed the unique, high precision and stable geomatics reference framework. The Multi Scales Fundamental datasets scaled from 1:1million to $1: 10,000$, and some areas such as the city centre of Shanghai, Tianjin and Beijing partly covered by 1:500 and 1:2000.

\begin{tabular}{|l|l|l|}
\hline Item & Name & Description \\
\hline 1 & $\begin{array}{l}\text { Coordinate } \\
\text { Reference Datum } \\
\text { Datasets }\end{array}$ & $\begin{array}{l}\text { The definition of reference } \\
\text { system including height } \\
\text { reference datum and special } \\
\text { reference datum. } \\
\text { Including 18 classes tile digital } \\
\text { map } \\
\text { Digital Map } \\
\text { Datasets } \\
\text { Geographic Entity } \\
\text { Place Name and } \\
\text { Address Datasets } \\
\text { The collections of place name } \\
\text { and address in Whole China } \\
\text { Including 0.5 30m resolution } \\
\text { satellite or air boned } \\
\text { photography image. The 30m } \\
\text { resolution is whole world coved. } \\
\text { The digital elevation in the form } \\
\text { of TIN } \\
\text { Street view and 3D digital } \\
\text { model of some cities (partly). }\end{array}$ \\
6 & $\begin{array}{l}\text { Image Datasets } \\
\text { Digital Elevation } \\
\text { Datasets } \\
\text { Building 3D } \\
\text { Models and Street } \\
\text { View Datasets } \\
\text { Thematic } \\
\text { Datasets }\end{array}$ & $\begin{array}{l}\text { Some thematic data relates to } \\
\text { people, industry etc. }\end{array}$ \\
\hline
\end{tabular}

Table 1. Brief view of Chinese NSDI Datasets components

The datasets used for the geoportal for public service are eight types: The Coordinate Reference datum, Digital Map Datasets, Geographic Entity, Place name and address datasets, Image datasets, Digital Elevation datasets, Building 3D models and street view datasets (partly), and Thematic datasets, as shown in table 1 .

\subsection{The Current Geoportal Services of Chinese NSDI}

The NASG provides online geoinformation services via the http://www.Tianditu (Mapworld).com or http://zhfw.Tianditu (Mapworld).cn/. The Tianditu (Mapworld) online platform provides multiple language services, including simple Chinese, English, Mongolia, and Weiwuer. The basic map of Tianditu (Mapworld) layers are: Geographic Entity (waters and railway), Image Map, Digital Map, and Topography.

Some added values are carried out and presented in the form of thematic applications. There are 33 types of thematic applications such as the silk road, the world surface cover, the population census, the weather forecast, the tourism, the system of national accounts review, the price index reveal, the peoples' living index analysis, the employment and salary analysis, etc. The Tianditu (Mapworld) platform free to provides 1353 service resources for public users. All the service resources can be indexed by keywords, and all available service resources have detailed metadata description. A brief view of the services of Tianditu (Mapworld) is presented in table 2.

\begin{tabular}{|l|l|l|}
\hline Item & Name & Description \\
\hline 1 & $\begin{array}{l}\text { Online } \\
\text { map } \\
\text { service } \\
\text { Composed } \\
\text { services } \\
\text { Cell phone } \\
\text { services }\end{array}$ & $\begin{array}{l}\text { Providing online digital map service for } \\
\text { view, search, and public transfer } \\
\text { interchange and plan. } \\
\text { Providing application services } \\
\text { combined with other thematic data. } \\
\text { Providing terminal smart client device } \\
\text { map services, including online } \\
\text { navigation, offline navigation data } \\
\text { download, app download, etc. } \\
\text { Providing access ports based on } \\
\text { JavaScript programming with OGC } \\
\text { standards. } \\
\text { Providing some typical application } \\
\text { cases based on Tianditu (Mapworld) } \\
\text { data in transportation, social services, } \\
\text { environmental protection, and } \\
\text { economy. } \\
\text { Providing online datasets service index } \\
\text { and data services description, as well as } \\
\text { the invoked standards (OGC). } \\
\text { Providing metadata information index } \\
\text { services. }\end{array}$ \\
\hline 6 & $\begin{array}{l}\text { Typical } \\
\text { application }\end{array}$ \\
\hline
\end{tabular}

Table 2. Brief view of the Tianditu (Mapworld) services

\subsection{The Advantage and Shortcomings of Data and Service}

Obviously, there are many advantages of Chinese NSDI data and services, such as: providing smart terminal accessing, providing some typical application cases, providing worldwide $30 \mathrm{~m}$ resolution image land cover services, and open APIs for further application development. However, there are still some shortages need to overcome:

(a) No datasets download services (except for the smart terminal navigation services). (b) The update of the datasets is not timely ( 999 out of 1353 datasets update frequency over 1 year, from Tianditu (Mapworld) website). (c) Cannot access all the metadata via internet. (d) Lack of strong tools for visional datasets operation (such as searching and downloading). (e) The category and list datasets are too coarse. (f) Lack of demo use of the APIs and correspond plugins. 
All these shortcomings will help us to adjust and improve the services by using the Backx model.

\section{THE RECOMMENDATION DATA AND SERVICE FRAMEWORK BASED ON BACKX MODEL}

According to the previous analysis, based on the Backx model, a recommendation model for Chinese NSDI is presented as figure 3 . In this recommendation model, the detailed important sub items of known, attainable and usable layers are discussed. The difference from the current Chinese NSDI data and services situation are:

(1) Regulate a category. And this category relates to arranged companies and ministries which should be responsible for the data collecting, processing (according unified standards), sharing and updating.

(2) Require timely update frequency. The important characteristic of the usable data is that keeping the datasets upto-date. The update frequency of the Tianditu (Mapworld) datasets is not timely, this will influence the application of the datasets.

(3) Improve the data quality and services. The data quality and services can be improved by using the five-star model. A relative good quality and services does at least reach 4 stars (Tim Berners-Lee, http://5stardata.info/en/).

(4) Make more applications based on Chinese NSDI datasets and services. The value of the datasets is characterized by the utilization of the data. More applications are built, and more added values appeal. The applications of the datasets can append to environment, economy, peoples' live, industry and education, etc. But one must clear, the applications should be integrated with the thematic datasets.

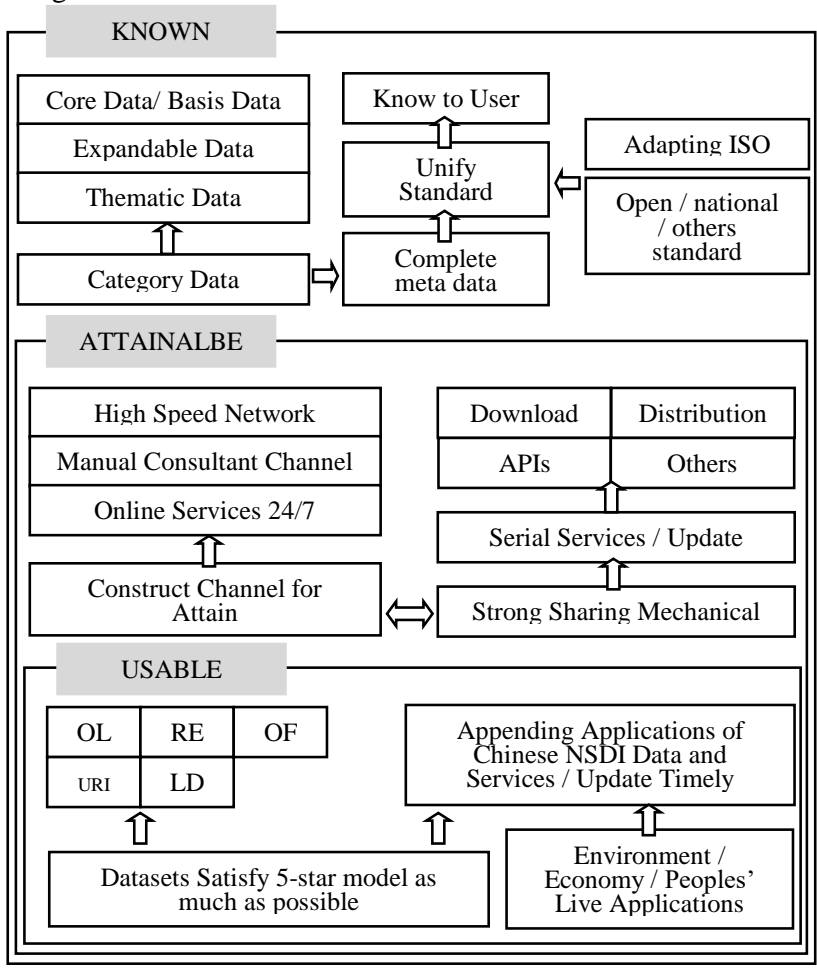

Figure 3. The technical framework of data and services
In Figure 3, OL, RE, OF, URI, LD represents 5-star model's parameters: OL - Open License; RE-Machine Readable; OFNon-proprietary (Open Format); URI-Universal Resource Identification; LD—Link data.

It should be noticed that the layers of framework of the data and services are inner connected. Different layers have their main functions, the known, attainable and usable clues are not isolated.

The known layer, focusing on the data and service descriptions and let the information be discoverable, must be well organized. According to the data and services objectives of Chinese NSDI, the data category must be clear, the datum reference and standards must be unified, and the metadata must be completed. Though the Current datasets of Chinese NSDI have classified eight types, however, the detailed description of the data structure cannot be find on Tianditu (Mapworld) website. It's not clear for the user how will find and further use of the datasets and services. According to the European INSPIRE experience and other European countries' experience (European Commission, 2014a, 2014b), modified datasets can be categorized into three groups: the core / basic data, the expendable data and thematic data. The core/basic datasets are responsible by NASG and the provincial, even municipal geoinformation administration departments. The expandable datasets, such as the street view data and navigation data, can be collected and provided by private companies, these companies can be constrained by legislation, and these data can be added to NSDI step by step. The thematic datasets, which are very important for thematic applications, can be dominated by powerful national ministries, and these ministries must be responsible for the thematic data qualities and updating. All the data and correspond organizations must be coordinated by legislations, only by this way, the accessing, sharing and using data can be reliable because of the support on laws.

In the attainable layer, the data must be existed and well organized. In order to improve the efficient and effective, a strong technical mechanism for data collection, sharing, distribution and consistent services must be constructed. In this mechanism, the data can be updated timely, and the date quality can be guaranteed. A possible creation/maintenance/sharing system is proposed in figure 4 .

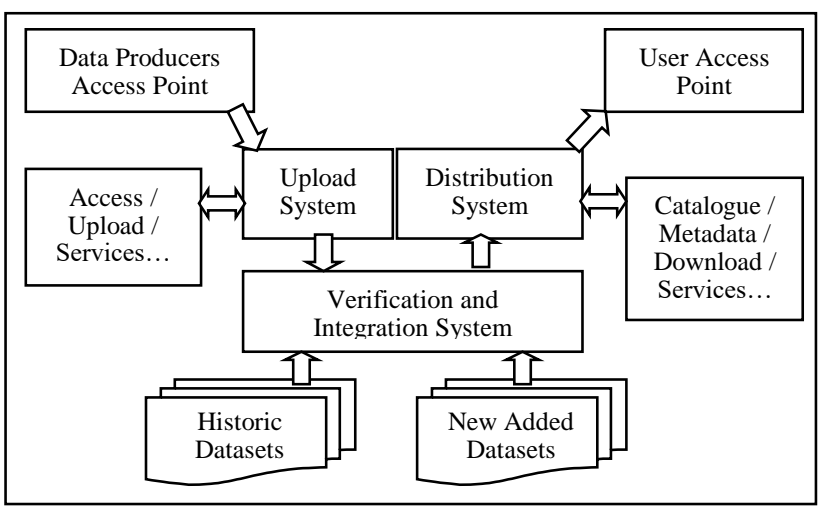

Figure 4. A technical creation/maintenance/sharing mechanism

From figure 4, there are three core systems: the upload system, the verification and integration system and the distribution system. The authorized data producers (public or private) can access the data upload system online $24 \mathrm{~h} / 7$ day, they can update the latest data to the specific datasets, the data can be quality 
inspected by the verification and integration system, the system can also integrate the new version data with the old one, and then a completed new version of up-to-data datasets can be distributed by the distribution system. By this way, a high effective data collecting, processing and sharing technical mechanism is constructed.

In the useable layer, there are some steps to make sure whether the data can be used or not. Before using the attained data, the data quality must be confirmed, and the method of the data utilization must be clear. Adding more values to the usable datasets are the final goals. A data checking mechanism is described as figure 5 .

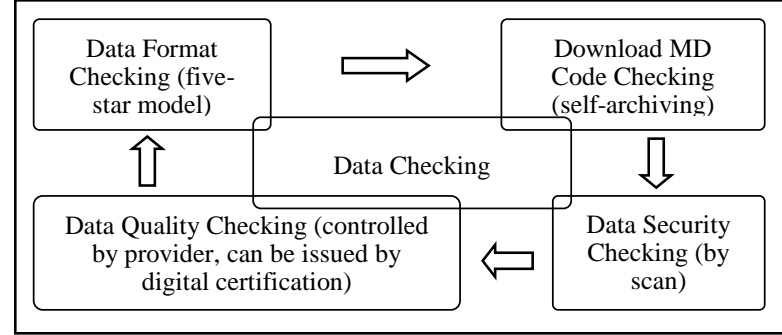

Figure 5. data checking Mechanism

From the above analysis, since there are some disadvantages, but the Chinese NSDI data and services still can be a very strong supporting tool for the China sustainable development. In China thirteenth five years plan, the environmental protection and ecological development are the core strategies. The pollution monitoring, ecological situation monitoring, and environmental accidents early warning, all those environmental and ecological issues which relates social and economy sustainable development can be solved assistantly by using SDI datasets and services combined with environmental and ecological thematic datasets (Rajabifard, 2012). Citizens will live a better life if the datasets and services, and the build-up applications based on them, push services and information directly to users with their demands and better life-living desire automatically.

\section{CONCLUSION}

The data and services analysis of Chinese NSDI is presented in this paper based on the current situation by using Backx model. some issues in the recommendation framework, such as the data category, the data and service collection, sharing and updating mechanism, the consistence of the standards and frame datum, the data checking and further added value applications are discussed and some possible recommendation models established, all those suggestions based on Backx model analysis can help improving the Chinese NSDI better data and application services, and it can also be referenced by national or local SDI for its better services.

\section{ACKNOWLEDGEMENT}

The achievement of this paper is sponsored by United Nations Committee of Experts on Global Geospatial Information Management (UN-GGIM) and China NASG from Aug 2015 to Mar 2016. Thanks for the guidance of Prof. Joep Crompvoets from University of Leuven (KU Leuven) and Dr. Bastiaan van Loenen from TU Delft.

This study is also funded by Key Laboratory of Geo-informatics of State Bureau of Surveying and Mapping in 2016.

\section{REFERENCES}

Bastiaan van Loenen, Michel Grothe. INSPIRE Empowers ReUse of Public Sector Information, International Journal of Spatial Data Infrastructures Research, 2014, Vol.9, pp.86-106.

Bastiaan van Loenen, Developing Geographic Information Infrastructure - The Role of Information Policies, 2016, Haveka, Alblasserdam, ISBN 90-407-2616-7, NUGI 755.

Backx, M. 2003. Gebouwgegevens redden levens. Toegankelijkheidseisen vangebouwgegevens in het kader van de openbare orde en veiligheid, MSc.Thesis, Delft University of Technology.

Deren Li, Jianya Gong, et.al. Establishment of spatial data infrastructure of China, Bulletin of Surveying,Vol 11,2002,pp.4-7.

Deren Li, Jianya Gong, et.al. Establishment of spatial data infrastructure of China, Bulletin of Surveying,Vol 12,2002,pp $1-4$.

European Commission, 2014a. Commission notice - Guidelines on recommended standard licences, datasets and charging for the reuse of documents, OJ 2014 C240/01.

European Commission, 2014b. Guidelines for the encoding of spatial data, Version 3.3, at http://inspire.ec.europa.eu/ documents/Data_Specifications/D2.7_v3.3.pdf.

Pengde Li, Lan Wu, Xuenian Xiao. 2008, SDI IN CHINA : PROGRESS AND ISSUES, The International Archives of the Photogrammetry, Remote Sensing and Spatial Information Science. Vol. XXXVII. Part B4. Beijing, 2008, pp.7-10.

Rajabifard, A, Feeney, M.E. and Williamson, 2002. Future directions for SDI Development. International Journal of Applied Earth Observation and Geoinformation, 4(1): pp.11-22

Rajabifard, A., 2012. Spatial data infrastructure. In: Steudler, D. and Rajabifard, A. eds. Spatially enabled society. Denmark: International Federation of Surveyors, pp.37-43.

van Loenen, B., Crompvoets, J., and A. Poplin, 2010. "Assessing geoportals from a user perspective", Proceedings of the GeoValue Workshop, September 30- October 22010 , Hamburg, Germany, at http://www.spatialist.be/download/pub/ IO0906039_CrompvoetsVanLoenen_2010_Geovalue_Hamburg .pdf.

http://zhfw.tianditu.com/

http://5stardata.info/en/ 